\title{
Latent Profiles of Performance on Certification Testing: The Case of Special Education Teachers in Saudi Arabia
}

\author{
Dimiter M. Dimitrov ${ }^{1,2, *}$, Abdullah Alsadaawi ${ }^{1,3}$ \\ ${ }^{1}$ National Center for Assessment, Riyadh, Saudi Arabia \\ ${ }^{2}$ George Mason University, Fairfax, Virginia, USA \\ ${ }^{3}$ King Saud University, Riyadh, Saudi Arabia
}

Copyright $(\mathrm{C} 2018$ by authors, all rights reserved. Authors agree that this article remains permanently open access under the terms of the Creative Commons Attribution License 4.0 International License

\begin{abstract}
This study investigates the performance of special education teacher candidates on key professional standards. Specifically, latent class analysis was used to identify latent (hidden) classes of teacher candidates based on their performance on professional standards measured by the Special Education Teacher Test for teacher certification in Saudi Arabia. The role of teachers' background variables in the formation of such latent classes was also examined. The results led to the retention of four latent profiles of teachers' performance on the targeted professional standards. Among other things, it was also found that the lowest performing latent class is dominated by males and teachers without professional training, whereas the highest performing latent class is dominated by females and teachers with professional training in special education. Implications for the practice and future research are discussed.
\end{abstract}

Keywords Latent Class Analysis, Special Education, Teacher Certification

\section{Introduction}

\subsection{Certification of Special Education Teachers}

The field of special education worldwide is marked by a large number of students, a growing need for highly qualified teachers, and more comprehensive understanding of the role of special education in the general framework of education. According to the National Center for Education Statistics, there are over six million special education students and close to a half a million special education teachers in the United States, yet the shortage of certified special education teachers is still quite substantial. Regarding the contribution of special education to our contemporary understanding of educational values, schooling and curriculum, some experts argue that "special education is not simply and only a separate part of education, it is inherently connected to all aspects of education" $[1, \mathrm{p} 85,2]$. The Counsel for Exceptional Children in the US provides special education professionals overseas with a broad spectrum of information services and professional development opportunities not available elsewhere [3].

A key element in the definition of highly qualified teachers is their certification. Under the terms of the No Child Left Behind (NCLB) Act in the US, "to be highly qualified teachers must: hold at least a bachelor's degree from a four-year institution; hold full state certification; and demonstrate competence in their subject area [4, p4].

The certification of special education teachers requires that they must know the basic principles of teaching in this field, principles centering on human growth and development, know the proper assessment tools to measure developmental functions and capabilities, know how to interpret results from commonly used assessments, and know how to design and maintain a safe and appropriate learning environment or classroom for their disabled students. In addition, certification tests address the basic characteristics for each of the major disability areas, and how these disabilities affect individuals, families, and society across the life span.

The process of teacher certification varies across states, with using licensure exams produced by Educational Testing Service (ETS), the National Evaluation Systems, and the American Board for Certification of Teacher Excellence. According to the ETS specifications of the certification test PRAXIS, the knowledge and skills measured by this test are grouped into four areas, (a) development and characteristics of students with intellectual disabilities, (b) planning and managing the learning environment, (c) instruction, (d) assessment, and (e) foundations and professional responsibilities. The context of special education and teacher 
certification in Saudi Arabia, which is of interest in this study, is described next.

\subsection{The Context in Saudi Arabia}

During the period of time from 1960 to 1971 , the special education programs in Saudi Arabia expended from limited services for children with disabilities to opening the Special Education Agency in the Ministry of Education. In 1971, the Ministry of Education opened the Intellectual Education Institute to provide special education, teacher training, and housing for boys and girls with severe intellectual disabilities [5].

In 2001, the Saudi government enacted Law Number 224-Regulations of Special Education Programs and Institutes (RSEPI) - which is aligned with the Individuals with Disabilities Education Act (IDEA 1990) in United States [6]. As described by Murry and Alqahtani [7, p58], "the RSEPI includes 11 Articles that provide for the special education and related services of children with disabilities. It outlines important definitions for teachers, school administrators, other service providers, and families for the education rights of students with disabilities. It includes explanations of the concepts of disability, least restrictive environment, transition services, multidisciplinary team, IEPs, special education teacher, resource room, and other aspects." For more information on the history and recent trends in the development of special education in Saudi Arabia, the reader may refer to extant research on this topic [8-11].

The focus on the human capital of teachers in Saudi Aribia is motivated by the Saudi "Vision 2030" [12] blueprint to modernize its economy and society and the substantial body of empirical evidence showing the importance of teacher quality for student achievement [13-14]. In 2010, the Saudi Ministry of Education concluded an agreement with the National Center for Assessment (NCA) to develop and conduct teacher certification tests. In 2011, the NCA signed a contract with the Tatweer company for educational services [15] to conduct a project with the aimed at improving the teaching profession. The project included the establishment of National Professional Teacher Standards (NPTS). The NPTS consists of 12 standards divided into two categories. The first category includes general standards that represent general teaching requirement, namely: professional knowledge, promoting learning, supporting learning and professional responsibility. The second category of NPTS includes subject-specific teaching standards that cover 28 teaching areas. The standards serve to guide the construction of new teacher licensure examinations, identify training needs for new teachers, and ensure the quality of teaching programs.

The Special Education Teacher Tests (SETTs) are developed and administered by the NCA in Saudi Arabia. These tests consist of one general test (SETT-G), required for all special education teacher candidates, and a specialty-oriented part, required for those who teach a given special education subject such as Autism, Behavioral therapy, Hearing impairment, Intellectual education, Learning difficulties, and Visual impairment. The SETTs are designed to reflect the new professional teacher standards, NPTS, described in the next section. During the last eight years, 27,266 special education teacher candidates $(16,761$ females and 10,505 males) have taken the SETTs for teaching certification.

\subsection{Purpose of the Study}

Regarding the SETT-G, which is used for the purposes of this study, the validity of the certification decisions based on SETT-G scores depend on the psychometric quality of the test and proper understanding of the teachers' performance on the targeted professional standards, NPTS, measured by the test. As a step in this direction, the main purpose of this study is to examine the performance of special education teacher candidates on the SETT-G test. One major task associated with this purpose is to identify latent (hidden) classes of teacher candidates based on their performance on the new teaching standards, NPTS, measured by the SETT-G. The role of teachers' background variables, such as gender, professional training, teaching experience, and area of specialty, in the formation of such latent classes is also investigated.

It should be noted that the testing for latent classes of special education teachers, based on their performance on a certification test, will avoid a common limitation in most if not all previous studies in this area (in US and other counties)-namely, the tacit assumption that the population of examinees is homogeneous in performance on a targeted set of test measures. However, given the complexity of factors that underlie the examinees' performance on a test, such an assumption is quite unrealistic and its violation may yield limited, misleading, and/or inconsistent findings across studies as it occurs in previous research [14,16-20]. In line with this purpose, the following research questions (RQs) are addressed here:

RQ1. Is the population of special education teachers homogeneous or it breaks into latent classes of teachers based on their performance on the teaching standards measured by the SETT-G test?

RQ2. What is the role of teachers' gender, training, experience, and specialty in the formation of latent classes of teachers?

\section{Method}

\subsection{Data}

The data in this study come from the scores of 12,193 special education teacher candidates on the SETT-G test as a part of their assessment for teaching certification in Saudi Arabia. The frequency distribution of teachers (count and 
percentage) by the five background variables available for this study (gender, training, teaching experience, and specialty) is provided in Table 1.

Table 1. Structure of the Study Sample

\begin{tabular}{|c|c|}
\hline Background variable & Count (\%) \\
\hline \multicolumn{2}{|c|}{ Gender } \\
\hline males & $5,358(43.9 \%)$ \\
\hline females & $6,835(56.1 \%)$ \\
\hline \multicolumn{2}{|c|}{ Training } \\
\hline No & $9,256(75.9 \%)$ \\
\hline Yes & $2,937(24.1 \%)$ \\
\hline \multicolumn{2}{|c|}{ Teaching Experience } \\
\hline No & $11,069(90.8 \%)$ \\
\hline Yes & $1,124(9.2 \%)$ \\
\hline \multicolumn{2}{|c|}{ Specialty } \\
\hline Autism & $1,366(11.2 \%)$ \\
\hline Behavioral therapy & $149(1.2 \%)$ \\
\hline Hearing impairment & $697(5.7 \%)$ \\
\hline Intellectual education & $697(5.7 \%)$ \\
\hline Learning difficulties & $5,425(44.5 \%)$ \\
\hline Visual impairment & $112(0.9 \%)$ \\
\hline
\end{tabular}

\subsection{Variables and Measures}

The SETT-G consists of 35 dichotomously scored items (1 $=$ correct, $0=$ incorrect) associated with the following nine teaching standards $(\mathrm{S} 1, \ldots, \mathrm{S} 9)$ :

S1: Concepts and specialized foundations (5 items),

S2: Stages and characteristics of growth and causes of disability (7 items),

S3: Impact of disability on learning (6 items),

S4: Measurement and evaluation (3 items),

S5: Educational alternatives, special education services, support and rehab program (3 items),

S6: General teaching methods (3 items),

S7: Behavioral educational program (3 items),

S8: Behavioral program (2 items), and

S9: Life skills (3 items).

The search for latent classes of teachers is based on their performance on the above nine teaching standards. For ease of interpretation, the teachers' scores on these standards are presented on the familiar T-scale (Mean $=50, S D=10)$. In addition, four background variables of the participants were used to investigate their role in the structure of the latent classes of teachers (if any): gender $(0=$ male, $1=$ female), professional training $(0=$ No, $1=$ Yes $)$, teaching experience $(0=$ No, $1=$ Yes $)$, and six areas of specialty (Autism, Behavioral therapy, Hearing impairment, Intellectual education, Learning difficulties, and Visual impairment).

\subsection{Statistical Analysis}

First, a confirmatory factor analysis (CFA) was used to test whether the SETT-G data are unidimensional; that is, there is one main dimension of ability (trait) that underlies the teacher's responses on the SETT-G items [21]. Unidimensionality of the data is required to validate the use of total scores on the SETT-G test and the estimation of score reliability for the test. Second, latent class analysis (LCA) [22-23] was used to test for latent classes of teachers based on their performance on the nine teaching standards described in the previous section (S1, . S9). Third, a chi-square test for dependence between two categorical variables was used to investigate the role of the background variables used in this study in the structure of latent classes of teachers. In each case, one the categorical variable was the latent classes of teachers and the other categorical variable was one of the background variables (gender, training, experience, and specialty).

\section{Results}

\subsection{Dimensionality of the SETT-G}

A one-factor CFA was tested for data fit to check for unidimensionality of the SETT-G data using the computer program Mplus [24]. A tenable data fit is indicated with the following rules for goodness-of-fit indices reported by default with Mplus, (a) statistically nonsignificant chi-square $\left(\chi^{2}\right)$, (b) comparative fit index, CFI $>0.90$, and (c) root-mean square error of approximation, RMSEA $<0.05$, with its $90 \%$ confidence interval entirely below $0.08[21,25]$. Under these rules, the examination of the following results indicates a tenable data fit of the one-factor CFA, with all 35 items of the SETT-G serving as indicators of a single factor in the CFA model, $\chi^{2}(d f=560)=2715.97, \mathrm{p}<0.001 ; \mathrm{CFI}=0.923$, RMSEA $=0.018$, with $90 \% \mathrm{CI}=(0.017,0.019)$.

\subsection{Reliability of SETT-G Scores}

The reliability of SETT-G scores is estimated here through the use of a popular latent variable modeling (LVM) approach taking into account the categorical nature of the binary scores $(1 / 0)$ on SETT-G items. The reader can find details on performing the LVM approach to estimation of score reliability in previous studies on this topic

[21,26-27]. The reliability of the SETT-G scores was found to be 0.744 , with a $95 \%$ confidence interval $(0.736$, 0.752 ), which is satisfactory for the purpose of the study.

\subsection{Latent Classes of Teachers}

A key step in the latent class analysis (LCA) is to decide how many latent classes of respondents to retain. This decision is based here on two widely recommended statistics, the Bayesian Information Criterion adjusted for sample size (aBIC) and the Lo-Mendel-Rubin Adjusted Likelihood Ratio Test (aLRT) [28]. The testing for number of latent classes starts with a single-class model and gradually increasing the number of latent classes until a decision of proper number of classes is reached. For technical details the reader may refer to Nylund, Asparouhov, and Muthén [29]. 


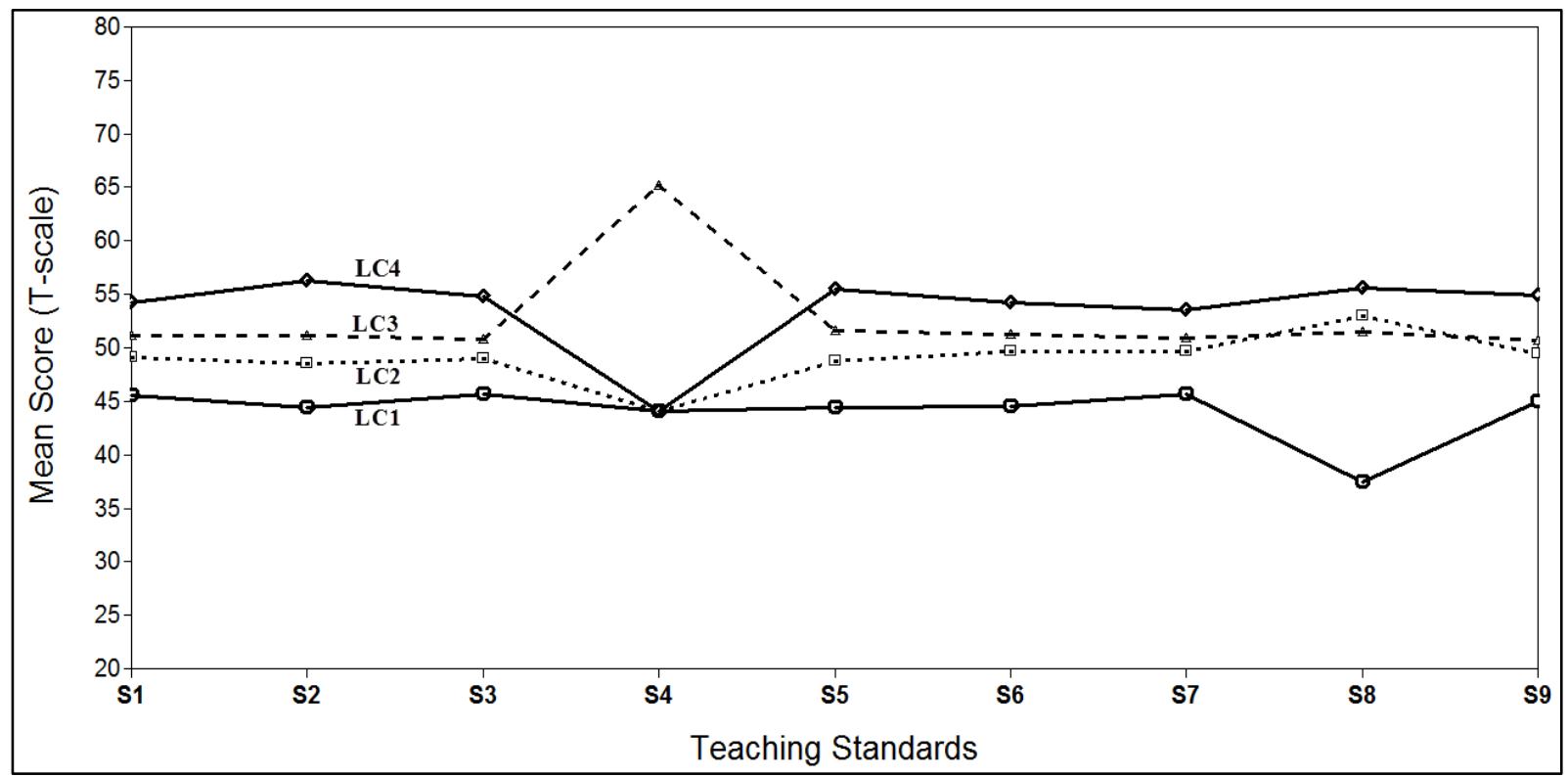

Figure 1. Four latent classes of teachers

In our case, four latent classes (LCs) were retained for subsequent analyses, with their profiles of performance on nine teaching standards depicted in Figure 1. The number of teachers by latent classes is as follows: $\mathrm{LC1}=2,386(19.6 \%)$, $\mathrm{LC} 2=4,111(33.7 \%), \mathrm{LC} 3=3,427(28.1 \%)$, and LC4 $=$ $2,269(18.6 \%)$. The LC1 is the lowest performing latent class, with a one-half standard deviation below the mean on the T-scale $($ Mean $=50, S D=10)$ and a sharp drop in performance on teaching standard S8 (Behavioral program). The highest performing latent class is LC4, with a one-half standard deviation below the mean on the T-scale, but with a surprising sharp drop in performance on teaching standard S4 (measurement and evaluation). On the other hand, the teachers in latent class LC3 demonstrate a sharp increase in performance on teaching standard S4.

Table 2. Percentage of Response Patterns on Three Test Items Related to Standard S4

\begin{tabular}{|c|c|c|c|c|}
\hline $\begin{array}{c}\text { Response } \\
\text { pattern }\end{array}$ & $\begin{array}{c}\mathrm{LC} 1 \\
\%\end{array}$ & $\begin{array}{c}\mathrm{LC} 2 \\
\%\end{array}$ & $\begin{array}{c}\mathrm{LC} 3 \\
\%\end{array}$ & $\begin{array}{c}\mathrm{LC} 4 \\
\%\end{array}$ \\
\hline 000 & 52.3 & 52.9 & 0 & 59.7 \\
\hline 100 & 47.7 & 47.1 & 0 & 40.3 \\
\hline 010 & 0 & 0 & 27.0 & 0 \\
\hline 001 & 0 & 0 & 23.8 & 0 \\
\hline 110 & 0 & 0 & 20.7 & 0 \\
\hline 101 & 0 & 0 & 18.2 & 0 \\
\hline 0111 & 0 & 0 & 6.1 & 0 \\
\hline 111 & 0 & 0 & 4.1 & 0 \\
\hline
\end{tabular}

Note. In each response pattern the items are ordered from easiest to most difficult, with $0=$ incorrect response, $1=$ correct response. The percentage of correct responses on these items (from left to right) is $45 \%, 16 \%$, and $15 \%$ for the study sample $(N=12,193)$. For example, the response pattern 100 indicates a correct response to the easiest test item and incorrect responses to the other two items.

The switch in performance on teaching standard S4 for the teachers in latent classes LC3 and LC4 deserves additional attention. One way is to examine the response patterns of teachers' responses $(0=$ incorrect, $1=$ correct $)$ on the three test items related to $\mathrm{S} 4$.

The frequencies of such response patterns are provided in Table 2.

\subsection{The Role of Background Variables}

The categories of the background variables used in this study were examined for proportional representation within latent classes using the chi-square $\left(\chi^{2}\right)$ test for dependence between two categorical variables [21, pp177-181]. If a statistically significant $\chi^{2}$ indicates such dependency, the standardized residuals (SRs) of the cells in the two-way table were used to test for overrepresentation (or underrepresentation) of males or females in the respective latent class. An overrepresentation is indicated by a statistically significant positive residual $(S R>1.96)$ and underrepresentation is indicated by a statistically significant negative residual $(S R<-1.96)$. The chi-square test results indicated statistically significant dependency between the latent classes of teachers and their (a) gender, $\chi^{2}(d f=3)=$ 921.60, $p<.001$, (b) training, $\chi^{2}(d f=3)=33.34, p<.001$, (c) experience, $\chi^{2}(d f=3)=9.46, p=0.024$, and (d) specialty, $\chi^{2}(d f=15)=358.10, p<.001$.

The examination of standardized residuals $(S R \mathrm{~s})$ in Table 3 revealed several main findings. First, the lowest performing latent class, LC1, is dominated by males, teachers without training, and teachers with specialty in Behavioral therapy, Learning difficulties, and Visual impairment. Second, latent class LC2 is not affected by the teachers' background variables; that is, there is balance in the frequency representation of the background variables within LC2.Third, latent class LC3 is dominated by females and teachers with specialty in Intellectual education. Fourth, latent class 
LC4 is dominated by females with training and specialty in Autism. Fifth, although the chi-square test indicated an overall statistical dependency between the latent classes of teachers and their teaching experience, the SR values do not indicate that some levels of teaching experience are overrepresented or underrepresented within a given latent class.

\section{Discussion}

\subsection{Main Findings}

This study investigates latent (hidden) classes of special education teachers based on their performance on teaching standards measured by the SETT-G certification test developed and administered by the National Center for Assessment in Saudi Arabia.

Table 3. Background Variables by Latent Classes of Teachers (LC1, LC2, LC3, LC4)

\begin{tabular}{|c|c|c|c|c|}
\hline Variable & LC1 & LC2 & LC3 & $\mathrm{LC} 4$ \\
\hline \multicolumn{5}{|c|}{ Gender } \\
\hline Males & $67.3 \%$ & $45.3 \%$ & $39.1 \%$ & $24.2 \%$ \\
\hline $\begin{aligned} & S R \\
= & \end{aligned}$ & $17.2^{*}$ & 1.3 & $-4.3^{*}$ & $-14.2 *$ \\
\hline Females & $32.7 \%$ & $54.7 \%$ & $60.9 \%$ & $75.8 \%$ \\
\hline$=\begin{aligned} & S R \\
= & \end{aligned}$ & $-15.2 *$ & -1.1 & $3.8^{*}$ & 12.5 \\
\hline \multicolumn{5}{|c|}{ Training } \\
\hline No & $79.1 \%$ & $76.6 \%$ & $75.4 \%$ & $72.1 \%$ \\
\hline$=\quad S R$ & 1.8 & 0.5 & -0.4 & $-2.1^{*}$ \\
\hline Yes & $20.9 \%$ & $23.4 \%$ & $24.6 \%$ & $27.9 \%$ \\
\hline$=S R$ & $-3.2^{*}$ & -1.0 & 0.6 & $3.7 *$ \\
\hline \multicolumn{5}{|c|}{ Specialty } \\
\hline Autism & $7.0 \%$ & $9.7 \%$ & $11.7 \%$ & $17.6 \%$ \\
\hline$=\quad S R$ & $-6.1^{*}$ & $-2.9^{*}$ & 0.8 & $9.1 *$ \\
\hline $\begin{array}{c}\text { Behavioral } \\
\text { therapy }\end{array}$ & $2.4 \%$ & $1.2 \%$ & $1.1 \%$ & $0.2 \%$ \\
\hline$=\quad S R$ & $5.2 *$ & 0.0 & -0.8 & $-4.3^{*}$ \\
\hline $\begin{array}{c}\text { Hearing } \\
\text { impairment }\end{array}$ & $5.4 \%$ & $5.8 \%$ & $5.3 \%$ & $6.7 \%$ \\
\hline$=\quad S R$ & -0.7 & 0.2 & -1.1 & 1.9 \\
\hline $\begin{array}{l}\text { Intellectual } \\
\text { education }\end{array}$ & $27.8 \%$ & $38.3 \%$ & $39.5 \%$ & $37.5 \%$ \\
\hline$=\quad S R$ & $-7.0^{*}$ & $2.0^{*}$ & $3.0^{*}$ & 0.8 \\
\hline $\begin{array}{c}\text { Learning } \\
\text { difficulties }\end{array}$ & $55.8 \%$ & $44.1 \%$ & $41.8 \%$ & 37.4 \\
\hline$={ }^{S R}$ & $8.3^{*}$ & -0.4 & $-2.3^{*}$ & $-5.1^{*}$ \\
\hline $\begin{array}{c}\text { Visual } \\
\text { impairment } \\
S R=\end{array}$ & $\begin{array}{l}1.6 \% \\
3.2 *\end{array}$ & $\begin{array}{c}0.9 \% \\
0.0 \\
\end{array}$ & $\begin{array}{c}0.6 \% \\
-1.7 \\
\end{array}$ & $\begin{array}{c}0.7 \% \\
-1.3 \\
\end{array}$ \\
\hline
\end{tabular}

* Statistically significant $S R(p<0.05)$

The role of teachers' background variables in such latent classes is also examined. The test for dimensionality of SETT-G data revealed that the data are unidimensional thus validating the use of a total test score for decisions on teacher certification.

The examination of performance profiles across teaching standards for different number of latent classes of teachers led to the retention of four latent classes with clearly distinguishable and interpretable profiles (Figure 1). The lowest performing latent class, LC1, is about one-half standard deviation below the mean on teaching standards, with the exception of a sharp drop in performance on standard S8 (Behavioral program). The highest performing latent class, LC4, is about one-half standard deviation above the mean on teaching standards, with the exception of a sharp drop in performance on standard S4 (Measurement and evaluation). Latent classes LC2 and LC3 are close to each other with performance around the mean on teaching standards, with the exception of a substantial increase in performance of the teachers in LC3 on standard S4 (measurement and evaluation).

In a search for explanation of the switch in performance on teaching standard S4 for the teachers in latent classes LC3 and LC4 (up and down, respectively), the response patterns on the three test questions (items) associated with S4 were examined. The results showed that the best performance on teaching standard S4 (Measurement and evaluation) is for the teachers in LC3, whereas the teachers in all other latent classes answered correctly only the easiest of all three questions related to S4. Also, it was found that latent class LC3 is dominated by females and teachers with specialty in Intellectual education, whereas latent class LC4 is dominated by females with training and specialty in Autism. The examination of curricula across the academic programs in special education revealed that more weight on measurement and evaluation is given in the program 'Intellectual disabilities' where, compared to other programs, the preparation of special education teacher candidates focuses more on using tests in special education, analyzing and interpreting data, making decision for diagnostic purposes based on assessment results, and so forth.

The overall findings about the role of background variables in the formation of latent classes of special education teacher candidates is that (a) the lowest performing latent class, LC1, is dominated by males, teachers without professional training, and teachers with specialty in Behavioral therapy, Learning difficulties, and Visual impairment, (b) the make up of latent class LC2 does not depend on the teachers' background variables used in this study, (c) latent class LC3 is dominated by females and teachers with specialty in Intellectual education, and (d) latent class LC4 is dominated by females with training and teachers with specialty in Autism.

\subsection{Implications}

An important implication from the findings in this study is that the curricula of special education teacher programs need to be more closely aligned with the new professional teacher standards, NPTS, in Saudi Arabia. An example of deficiency 
in this regard is the relatively low performance (half a standard deviation below the average) on the NPRS for measurement and evaluation of special education teacher candidates, with the exception of those who study in the program 'Intellectual disabilities.' It should be noted that this issue has been noticed with special education programs in other countries as well. For example, referring to research on this issue in the US, Hollenbeck and Tindal [19] stated that "Shepard's [30] research determined that neither school psychologists nor teachers of children with learning disabilities were likely to be competent in their knowledge and application of assessment. Corroborating Shepard's conclusions, Siskind [31, p176] found that "special educators were not well informed about assessment and assessment procedures. Consequently, classroom teachers who lack collegiate training in assessment may not be able to rely on their school resource personnel as an expert source of assistance on accommodation issues."

Another implication stemming from the finding that the highest performing latent classes, LC3 and LC4, of special education teacher candidates are dominated by females, whereas the lowest performing latent class, LC1, is dominated by males (see Figure 1). Therefore, given the gender segregated education in Saudi Arabia, there is a need for a closer look at differences in factors such as curricula, training, attitudes toward special education [32-33] that contribute to gender difference in the latent profiles of performance on the new professional teacher standards measured by the TTSE-G certification assessment.

\subsection{Future Research}

The above implications from the main findings in this study call for future research related to design and implementation of policies and procedures in the education and training of special education teacher candidates in Saudi Arabia. The use of mixed research methods (both quantitative and qualitative) would be appropriate for such future studies to provide in-depth understanding of the phenomena under investigation. Along with this, an ongoing research on the measurement quality and further development of the TTSE-G assessment is needed to ensure validity of certification decisions based on the performance of special education teacher candidates on the TTSE-G assessment. Also, an useful follow-up could be a discussion of the curriculum associated with the courses related to the teacher certification assessment. A study on how the performance of special education teachers in their subsequent practice as teachers (e.g., academic success of their students) relate to their performance on the TTSE (general and specialty) certification tests would be also very informative for the predictive validity of these tests.

\subsection{Conclusion}

We trust that the findings in this study can be very useful to researchers, educators, and policy makers in Saudi Arabia regarding the preparation of special education teacher candidates and their certification. Along with this, the research methodology used here can be useful to researchers in the field of special education across countries with different educational and cultural context.

\section{REFERENCES}

[1] Corbett, J., \& Norwich, B. (1998). The contribution of special education to our understanding of values, schooling and the curriculum. Curriculum Studies, 6(1), 85-96.

[2] Gargiulo, R. M., \& Bouck, E. C. (2017). Special education in contemporary society: An introduction to exceptionality (6th ed.). Sage Publishing.

[3] Counsel for Exceptional Children in the US, Available online from

https://www.cec.sped.org/Special-Ed-Topics/International-S pecial-Education.

[4] U.S. Department of Education. (2003). Meeting the highly qualified teachers challenge: The secretary's second annual report on teacher quality. Available online from https:/www2.ed.gov/about/reports/annual/teachprep/2003titl e-ii-report.pdf.

[5] Aldabas, R. A. (2015). Special education in Saudi Arabia: History and areas for reform. Creative Education 6, 1158-1167.

[6] Ministry of Education of Saudi Arabia (2002). Rules and regulations of special education. Available online from https://www.moe.gov.sa/Arabic/PublicAgenciesAndDepartm ents/BoysEducationAgency/SpecialEducation/DocumentsLi braries/RulesAndRegulations/se_rules.zip

[7] Murry, F., \& Alqahtani, R. M. A. (2015). Teaching special education law in Saudi Arabia: improving pre-service teacher education and services to students with disabilities. World Journal of Education, 5(6), 57-64.

[8] Alharbi, A., \& Madhesh, A. (2018). Inclusive education and policy in Saudi Arabia. International Journal of Education Research and Reviews 6(1), 946-956.

[9] Alnahdi, G. H. (2014). Educational change in Saudi Arabia. Journal of International Education Research, 10(1), 1-6.

[10] Alquraini, T. (2010). Special education in Saudi Arabia: Challenges, perspectives, future possibilities. International Journal of Special Education, 25, 139-147.

[11] Battal, Z. M. B. (2016). Special education in Saudi Arabia. International Journal of Technology and Inclusive Education, 5 (2), 880-886.

[12] Vision 2030, Available online from http://vision2030.gov.sa/en.

[13] Aaronson, D., Barrow L., \& Sander, W. (2007). Teachers and student achievement in the Chicago public high schools. Journal of Labor Economics 25(1), 95-135.

[14] Goldhaber, D., \& Hansen, M. 2010). Race, gender, and teacher testing: How informative a tool is teacher licensure testing? American Educational Research Journal, 47(1), 
$218-251$.

[15] Tatweer Company for Educational Services, Available online from https://www.t4edu.com/en.

[16] Boe, E., Shin, S. \& Cook, L. H. (2007). "Does teacher preparation matter for beginning teachers in either special or general education? The Journal of Special Education, 41(3), 158-170.

[17] Brock, M. E., \& Carter, E. W. (2015). Effects of a professional development package to prepare special education paraprofessionals to implement evidence-based practice. The Journal of Special Education, 49(1), 39-51.

[18] Hadadian, A., \& Chiang, L. (2007). Special education training and preservice teachers. International Journal of Special Education, 22(1), 103-106.

[19] Hollenbeck, K., \& Tindal, G. (1998). Teachers' knowledge of accommodations as a validity issue in high-stakes testing. The Journal of Special Education, 32(3), 175-183.

[20] Stotsky, S. (2009). Licensure tests for special education teachers: How well they assess knowledge of reading instruction and mathematics. Journal of Learning Disabilities, 42(5), 464-474.

[21] Dimitrov, D. M. 2012. Statistical Methods for Validation of Assessment Scale Data in Counseling and Related Fields. Alexandria, VA: American Counseling Association.

[22] Hagenaars, J. A., \& McCutcheon, A. A. (2002). Applied latent class analysis. Cambridge, UK: Cambridge University Press.

[23] Lubke, G. H., \& Muthén, B. (2005). Investigating population heterogeneity with factor mixture models. Psychological Methods, 10(1), 21-39.

[24] Muthén, L. K., \& Muthén, B. O. (2012). Mplus user's guide (7th ed.). Los Angeles, CA: Muthén \& Muthén, Author.

[25] Hu, L. T., \& Bentler, P. M. (1999). Cutoff criteria for fit indexes in covariance structure analysis: Conventional criteria versus new alternatives. Structural Equation Modeling, 6(1), 1-55.

[26] Dimitrov, D. M., \& Shamrani, A. (2015). Psychometric features of the General Aptitude Test-Verbal Part (GAT-V): A large-scale assessment of high school graduates in Saudi Arabia. Measurement and Evaluation in Counseling and Development, 48(2), 79-94.

[27] Raykov, T. (2007). Evaluation of weighted scale reliability and criterion validity: A latent variable modeling approach. Measurement and Evaluation in Counseling and Development, 40(1), 42-52.

[28] Tofghi, D., \& Enders, C. K. (2007). Identifying the correct number of classes in mixture models. In G. R. Hancock \& K. M. Samuelsen (Eds,), Advances in latent variable mixture models (pp. 317-341). Greenwich, CT: Information Age.

[29] Nylund, K. L., Asparouhov, T., \& Muthén, B. O. (2007. Deciding on the number of classes in latent class analysis and growth mixture modeling: A Monte Carlo simulation study. Structural Equation Modeling, 14(4), 536-569.

[30] Shepard, L. (1983). The role of measurement in educational policy: Lessons from the identification of learning disabled. Educational Measurement: Issues and Practice, 2(3), 48.

[31] Siskind, T. G. (1993). Teachers' knowledge about tests modifications for students with disabilities. Diagnostique, 18(2), 145-157.

[32] Almalki, N. (2017). Perspectives of Saudi special education teachers towards secondary and post-secondary transition services for youth with multiple disabilities. International Journal for Research in Education, 41(1), 304-337.

[33] Evans, D., \& Alharti, N. (2017). Special education teachers' attitudes towards teaching students with learning disabilities in middle schools in Saudi Arabia. International Journal of Modern Education Studies, 1(1), 1-13 